\title{
Current state of glycemic control in critically ill subjects in a general intensive care unit
}

This article was published in the following Dove Press journal:

International Journal of General Medicine

6 January 2012

Number of times this article has been viewed

\author{
Vasileios Zochios' \\ Jonathan Wilkinson ${ }^{2}$ \\ Jonathan Perry' \\ 'University Hospitals of Leicester \\ NHS Trust, Leicester, UK; \\ ${ }^{2}$ Northampton General Hospital NHS \\ Trust, Northampton, UK
}

\begin{abstract}
Critically ill patients are predisposed to stress-induced hyperglycemia. Recent evidence suggests that uncontrolled hyperglycemia is associated with poor outcomes within the population of surgical and medical intensive care units. We retrospectively audited our practice in the management of hyperglycemia in the critically ill, in order to identify reasons and periods of time that deviations in blood glucose control are most likely, and to make recommendations on how to improve this. Our study showed poor compliance with the current recommendations for glycemic control in the critically ill and highlighted the need for a successful protocol for glycemic control in our institution. That should be carefully coordinated with the level of nutritional support and metabolic status of the acutely ill patient.
\end{abstract}

Keywords: hyperglycemia, critical illness, glycemic control, mortality

\section{Introduction}

Hyperglycemia and insulin resistance are common in critically ill patients and more pronounced among patients having sepsis, burns, trauma, and cardiothoracic surgery. ${ }^{1}$ Hyperglycemia was previously considered an adaptive response essential for survival and was not routinely controlled in intensive care units (ICUs). ${ }^{2,3}$ However, more recent evidence suggests that hyperglycemia in critically ill patients is associated with worse outcomes. Multiple randomized control trials have evaluated the role of intensive insulin therapy in intensive care patients. ${ }^{4-17}$ From these studies controversy exists with regards to the target blood glucose level during insulin therapy. Several studies have evaluated glycemic control in surgical, medical and mixed ICU patient populations.

The largest surgical trial was performed by Van den Berghe and colleagues and was a randomized study of 1548 adult surgical patients receiving mechanical ventilation on ICU (62\% had undergone cardiothoracic surgery) who were randomized to conventional blood glucose management or intensive insulin therapy. ${ }^{9}$ Insulin therapy was initiated when the blood glucose concentration reached $12 \mathrm{mmol} / \mathrm{L}$ in the conventional group versus $6.1 \mathrm{mmol} / \mathrm{L}$ in the intensive treatment group and the target range was $10-11.1 \mathrm{mmol} / \mathrm{L}$ ( 180 to $200 \mathrm{mg} / \mathrm{dL}$ ) in the conventional group compared to $4.4-6.1 \mathrm{mmol} / \mathrm{L}$ ( 80 to $110 \mathrm{mg} / \mathrm{dL}$ ) in the intensive insulin therapy group. All patients were given 200 to $300 \mathrm{~g}$ of intravenous glucose during the first 24 hours of ICU admission, with aggressive nutritional support to reach the caloric goal by ICU day 2 (the majority with mixed enteral and parenteral nutrition). A 12 month risk reduction in mortality of $43 \%(P<0.036)$ was demonstrated in the intensive therapy cohort.
Correspondence: Vasileios Zochios University Hospitals of Leicester NHS Trust, Leicester General Hospital Department of Anaesthesia and Critical Care, Gwendolen Road, Leicester, Leicestershire, LE5 4PW, UK

Email vasileioszochios@doctors.org.uk 
Risk reductions in this group were also seen for other outcomes including a $46 \%$ risk reduction in bloodstream infections. This study, however, had several limitations and differences from daily practice. First, the overall ICU hospital mortality rate was large in the control group, which may have confounded the benefit of intensive insulin therapy. In addition, the large infusion of glucose during the first 24 hours of ICU admission followed by aggressive nutrition may have additionally benefited the intensive insulin group as they were rescued by early aggressive therapy.

The Leuven Medical was the only large randomized trial that evaluated the effect of glycemic control in medical ICU patients and assigned 2000 patients to intensive insulin therapy or conventional glucose management. ${ }^{10}$ As in the surgical trial, intensive therapy targeted a blood glucose level of 80 to $110 \mathrm{mg} / \mathrm{dL}$, whereas conventional therapy targeted a blood glucose level of 180 to $200 \mathrm{mg} / \mathrm{dL}$. The glucose infusion in the first 24 hours was followed by intensive nutritional management. The insulin protocols were identical to the surgical trial. Intensive insulin therapy did not significantly change overall mortality when compared with conventional management. However, the intensive insulin therapy arm had a higher mortality when ICU stay was shorter than 3 days but was associated with reduced mortality if longer than 3 days. Intensive therapy was also associated with reduced acute kidney injury rate, duration of mechanical ventilation, ICU length of stay, and total hospital length of stay. Hypoglycemia was much more common in the intensive therapy group.

The most robust trial to date is the multicenter Normoglycemia in Intensive Care Evaluation Survival Using Glucose Algorithm Regulation (NICE-SUGAR) trial which raised the question of potential treatment-related harm and also documented significant hypoglycemia. The NICE-SUGAR trial randomly assigned 6022 medical and surgical ICU patients to either intensive insulin therapy (target blood glucose level of 81 to $108 \mathrm{mg} / \mathrm{dL}$ [4.5-6 mmol/L]) or conventional glucose control (target blood glucose of $<180 \mathrm{mg} / \mathrm{dL}[<10 \mathrm{mmol} / \mathrm{L}]$ ). ${ }^{9}$ Although the conventional glucose group was defined only by a maximal blood glucose target, the insulin infusion was reduced and then discontinued if the blood glucose level dropped below $144 \mathrm{mg} / \mathrm{dL}$ ( $8.0 \mathrm{mmol} / \mathrm{L})$. The intensive insulin therapy group had a significantly higher 90 day mortality and significantly higher incidence of severe hypoglycemia, defined as blood glucose $<40 \mathrm{mg} / \mathrm{dL}(2.2 \mathrm{mmol} / \mathrm{L})$. Therefore, a blood glucose target of $8.0-10 \mathrm{mmol} / \mathrm{L}(144-180 \mathrm{mg} / \mathrm{dL})$ rather than a more stringent target (eg, 81-108 mg/dL [4.5-6.0 mmol/L]) or a more liberal target (eg, 180-200 mg/dL [10-11.1 mmol/L]), avoids marked hyperglycemia, while minimizing the risk of both iatrogenic hypoglycemia and other harms associated with a lower blood glucose target.

\section{Materials and methods}

The purpose of the study was to record blood glucose concentrations, in patients admitted to a general ICU, for the first 48 hours after ICU admission and compare the results to an audit standard of 8.0-10.0 mmol/L, based on the NICESUGAR study and international recommendations for glycemic control in critically ill patients. ${ }^{10}$ We aimed to identify reasons and periods of time where deviations in blood glucose control are most likely and to make recommendations on how to improve this. We decided to undertake this clinical audit because the findings of the Van den Berghe studies were not replicated by other investigators and we were concerned that the widely accepted Van den Berghe approach for intensive blood glucose control increases mortality, as reported by the NICE-SUGAR trial and recent meta-analyses. ${ }^{11,18}$ Our aim: to change current practice and patient care in accordance with the latest recommendations and evidence based medicine.

A retrospective review of 20 patients receiving mechanical ventilation in an eight-bedded general (medical-surgical) ICU of a district general hospital was conducted. An audit tool was developed to evaluate the pattern of glycemic control over time and data was collected from the ICU observation charts for the first 48 hours after ICU admission. Blood samples for glucose measurement were obtained by means of arterial catheters, and intravenous infusion of insulin in saline was used for control of blood glucose. All these patients received intravenous fluids in a traditional manner and after vital signs became stabilized, enteral nutritional support was provided as soon as possible.

\section{Results}

Data was collected from a total of 20 patients. Sixty-five percent (13) of these were male and the majority of the patients $(55 \%)$ were aged between 70 and 80 years old. Fifteen percent (3) of these patients were diabetics and $45 \%$ (9) were surgical patients. All 20 patients were mechanically ventilated for a minimum period of 48 hours. The average frequency of blood glucose monitoring was 2.6 hours. The mean number of blood glucose samples per patient in 48 hours was 18.45. Twenty percent of the patients received intravenous infusion of insulin in order to achieve glycemic control. Only $22.2 \%$ of the patients with blood glucose level greater than $10 \mathrm{mmol} / \mathrm{L}$, received insulin. Only $15 \%$ of the patients with blood sugar level less than $8 \mathrm{mmol} / \mathrm{L}$ received enteral nutrition. One case of hypoglycemia was seen (blood glucose 


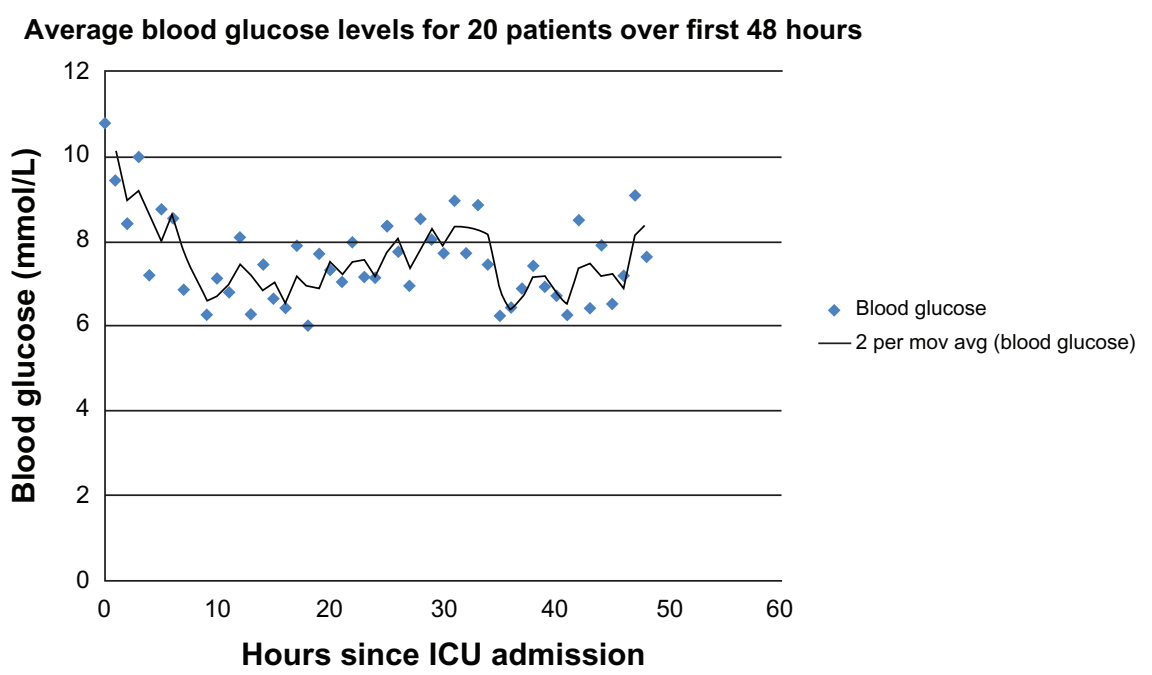

Figure I Pattern of glycemic control in our ICU for the first 48 hours after ICU admission. Abbreviation: ICU, intensive care unit.

level, $\leq 40 \mathrm{mg} / \mathrm{dL}[2.2 \mathrm{mmol} / \mathrm{L}])$ in a non-diabetic patient being treated with an insulin infusion. None of the patients met the standard of $8.0-10.0 \mathrm{mmol} / \mathrm{L}$ for the audit period of 48 hours. Figure 1 shows the pattern of glycemic control in our ICU for the first 48 hours after ICU admission.

\section{Discussion}

Hyperglycemia is associated with poor clinical outcomes in critically ill patients. Too tight a target blood sugar range is difficult to meet and may be leading to more morbidity due to hypoglycemic episodes. For hyperglycemic critically ill patients we recommend a blood glucose target of 8.0-10 mmol/L (144-180 mg/dL). To achieve this target we suggest that use of intravenous fluids that contain glucose should be minimized and administration of insulin be commenced if blood glucose exceeds $10.0 \mathrm{mmol} / \mathrm{L}(180 \mathrm{mg} / \mathrm{dL})$, and adjusted when needed to maintain blood glucose of 8.0-10.0 mmol/L (144-180 mg/dL). Our purpose is to design a successful protocol for glycemic control in our institution. The majority of suggested protocols demand a minimum of hourly glucose monitoring for successful glycemic target achievement while reducing the risk of hypoglycemia. ${ }^{19}$ For the implementation of insulin protocols for strict glycemic control in our ICU, there is a need for an automated continuous vascular blood glucose monitor which is still undergoing evaluation in the United Kingdom. ${ }^{20}$ The strategy of glycemic control should be carefully coordinated with the level of nutritional support and metabolic status of the critically ill patient. We suggest an uninterrupted feeding regime in order to avoid hypoglycemia, which is an independent risk factor for death after adjustment for age, severity of illness, diabetes, renal failure, and mechanical ventilation. ${ }^{21}$ Thus, glucose control protocols should include specific algorithms for managing hypoglycemic events in critically ill patients. Early glucose control has the potential to reduce ICU or hospital length of stay for all patients admitted to the ICU. By ensuring compliance, developing protocols and incorporating a multidisciplinary approach, clinicians will achieve blood glucose control in the critically ill population and improve outcomes. A re-audit will be performed 6 months after implementation of changes.

\section{Disclosure}

The authors report no conflicts of interest in this work.

\section{References}

1. Groeneveld ABJ, Beishuizen A, Visser FC, et al. Insulin: a wonder drug in the critically ill? Crit Care. 2002;6:102-105.

2. Chinsky K. The evolving paradigm of hyperglycaemia and critical illness Chest. 2004;126:674-676.

3. Robinson LE, van Soeren MH. Insulin resistance and hyperglycaemia in critical illness: role of insulin in glycaemic control. AACN Clin Issues. 2004; 15:45-62.

4. Bochicchio GV, Sung J, Joshi M, et al. Persistent hyperglycemia is predictive of outcome in critically ill trauma patients. $J$ Trauma. 2005;58(5):921-924

5. Sung J, Bochicchio GV, Joshi M, Bochicchio K, Tracy K, Scalea TM. Admission hyperglycemia is predictive of outcome in critically ill trauma patients. J Trauma. 2005;59:80-83.

6. Laird AM, Miller PR, Kilgo PD, Meredith JW, Chang MC. Relationship of early hyperglycemia to mortality in trauma patients. J Trauma. 2004;56(5):1058-1062.

7. Jeremitsky E, Omert LA, Dunham CM, Wilberger J, Rodriguez A. The impact of hyperglycemia on patients with severe brain injury. J Trauma. 2005;58:47-50.

8. Ichai C, Preiser JC. SFAR, SRLF Experts Group. International recommendations for glucose control in adult non diabetic critically ill patients. Crit Care. 2010;14(5):R166. 
9. Van den Berghe G, Wouters P, Weekers F, et al. Intensive insulin therapy in the critically ill patients. $N$ Engl J Med. 2001;345:1359-1367.

10. Van den Berghe G, Wilmer A, Hermans G, et al. Intensive insulin therapy in the medical ICU. $N$ Engl J Med. 2006;354:449-461.

11. Griesdale DE, de Souza RJ, van Dam RM, et al. Intensive insulin therapy and mortality among critically ill patients: a meta-analysis including NICE-SUGAR study data. CMAJ. 2009;180:821-827.

12. Finfer S, Chittock DR, Su SY, et al. NICE-SUGAR study investigators. Intensive versus conventional glucose control in critically ill patients. N Engl J Med. 2009;360:1283-1297.

13. Brunkhorst FM, Engel C, Bloos F, et al. German competence network sepsis. Intensive insulin therapy and pentastarch resuscitation in severe sepsis. N Engl J Med. 2008;358:125-139.

14. Preiser JC, Devos P, Ruiz-Santana S, et al. A prospective randomised multi-centre controlled trial on tight glucose control by intensive insulin therapy in adult intensive care units: the glucontrol study. Intensive Care Med. 2009;35(10):1738-1748.

15. Arabi YM, Dabbagh OC, Tamim HM, et al. Intensive versus conventional insulin therapy: a randomized controlled trial in medical and surgical critically ill patients. Crit Care Med. 2008;36:3190-3197.
16. Krinsley JS. Association between hyperglycemia and increased hospital mortality in a heterogeneous population of critically ill patients. Mayo Clin Proc. 2003;78:1471-1478.

17. Preiser JC, Devos P. Steps for the implementation and validation of tight glucose control. Intensive Care Med. 2007;33:570-571.

18. Wiener RS, Wiener DC, Larson RJ. Benefits and risks of tight glucose control in critically ill adults: a meta-analysis. JAMA. 2008;300(8): 933-944.

19. Goldberg PA, Siegel MD, Sherwin RS, et al. Implementation of a safe and effective insulin infusion protocol in a medical intensive care unit. Diabetes Care. 2004;27(2):461-467.

20. Weiss R, Lazar I. The need for continuous blood glucose monitoring in the intensive care unit. J Diabetes Sci Technol. 2007;1(3):412-414.

21. Krinsley JS, Grover A. Severe hypoglycemia in critically ill patients: risk factors and outcomes. Crit Care Med. 2007;35:2262-2267.

\section{Publish your work in this journal}

The International Journal of General Medicine is an international, peer-reviewed open-access journal that focuses on general and internal medicine, pathogenesis, epidemiology, diagnosis, monitoring and treatment protocols. The journal is characterized by the rapid reporting of reviews, original research and clinical studies across all disease areas.
A key focus is the elucidation of disease processes and management protocols resulting in improved outcomes for the patient.The manuscript management system is completely online and includes a very quick and fair peer-review system. Visit http://www.dovepress.com/ testimonials.php to read real quotes from published authors.

Submit your manuscript here: http://www.dovepress.com/international-journal-of-general-medicine-journal 